\title{
MicroRNA-34a-5p expression in the plasma and in its extracellular vesicle fractions in subjects with Parkinson's disease: An exploratory study
}

\author{
ILARIA GROSSI $^{1 *}$, ANNALISA RADEGHIERI $^{1 *}$, LUCIA PAOLINI $^{1,2}$, VANESSA PORRINI $^{1}$, \\ ANDREA PILOTTO $^{3}$, ALESSANDRO PADOVANI $^{3}$, ALESSANDRA MARENGONI $^{4}$, ALESSANDRO BARBON $^{1}$, \\ ARIANNA BELLUCCI ${ }^{1}$, MARINA PIZZI $^{1}$, ALESSANDRO SALVI ${ }^{1}$ and GIUSEPPINA DE PETRO ${ }^{1}$ \\ ${ }^{1}$ Department of Molecular and Translational Medicine, University of Brescia, I-25123 Brescia; \\ ${ }^{2}$ Consorzio Sistemi a Grande Interfase (CSGI), Department of Chemistry, University of Florence, \\ I-50019 Sesto Fiorentino (FI); ${ }^{3}$ Neurology Unit and ${ }^{4}$ General Medicine and Geriatrics Unit, \\ Department of Clinical and Experimental Sciences, University of Brescia, I-25123 Brescia, Italy
}

Received July 23, 2020; Accepted November 9, 2020

DOI: $10.3892 /$ ijmm.2020.4806

\begin{abstract}
Parkinson's disease (PD) is an important disabling age-related disorder and is the second most common neurodegenerative disease. Currently, no established molecular biomarkers exist for the early diagnosis of PD. Circulating microRNAs (miRNAs), either vesicle-free or encapsulated in extracellular vesicles (EVs), have emerged as potential blood-based biomarkers also for neurodegenerative diseases. In this exploratory study, we focused on miR-34a-5p because of its well-documented involvement in neurobiology. To explore a differential profile of circulating miR-34a-5p in PD, PD patients and age-matched control subjects were enrolled. Serial ultracentrifugation steps and density gradient were used to separate EV subpopulations from plasma according
\end{abstract}

Correspondence to: Professor Alessandro Salvi or Professor Giuseppina De Petro, Department of Molecular and Translational Medicine, University of Brescia, Viale Europa 11, I-25123 Brescia, Italy E-mail: alessandro.salvi@unibs.it

E-mail: giuseppina.depetro@unibs.it

${ }^{*}$ Contributed equally

Abbreviations: PD, Parkinson's disease; miRNAs, microRNAs; EVs, extracellular vesicles; CSF, cerebrospinal fluid; ISEV, International Society for Extracellular Vesicles; LEVs, large extracellular vesicles; MEVs, medium extracellular vesicles; SEVs, small extracellular vesicles; EPCs, exogenous protein contaminants; MISEV, minimal information for studies of extracellular vesicles; WB, western blotting; ESCRT, Endosomal Sorting Complexes Required for Transport; AFM, atomic force microscopy; CONAN, COlorimetric NANoplasmotic assay; NCS, nervous central system; AUC, area under curve; BDI, Beck depression inventory; UPDRS, unified Parkinson disease rating scale

Key words: Parkinson's disease, human plasma, extracellular vesicles, microRNAs, miR-34a-5p to their different sedimentation properties (Large, Medium, Small EVs). Characterization of EV types was performed using western blotting and atomic force microscopy (AFM); purity from protein contaminants was checked with the colorimetric nanoplasmonic assay. Circulating miR-34a-5p levels were evaluated using qPCR in plasma and in each EV type. miR-34a-5p was significantly up-regulated in small EVs devoid of exogenous protein contaminants (pure SEVs) from PD patients and ROC analysis indicated a good diagnostic performance in discriminating patients from controls (AUC $=0.74, \mathrm{P}<0.05$ ). Moreover, miR-34a-5p levels in pure SEVs were associated with disease duration, Hoehn and Yahr and Beck Depression Inventory scores. These results underline the necessity to examine the miRNA content of each EV subpopulation to identify miRNA candidates with potential diagnostic value and lay the basis for future studies to validate the overexpression of circulating miR-34a-5p in PD via the use of pure SEVs.

\section{Introduction}

Parkinson's disease (PD) is the second most common neurodegenerative disease worldwide affecting $1 \%$ of the population that is over 60 years of age. The main pathological feature is the progressive loss of dopaminergic neurons of the substantia nigra in the mid-brain region. PD is characterized clinically by several motor signs, including bradykinesia, rigidity, tremor, and postural instability, but also by non-motor symptoms such as dementia and sleep and mood disorders. The intraneuronal accumulation and misfolding of $\alpha$-synuclein is a well-characterized mechanism that leads to dopaminergic neurotoxicity (1-3). It is known that PD onset is strongly associated with age and its clinical diagnosis is difficult, in particular during the earlier stages of the disease, when the risk of misdiagnosis between PD and other neurodegenerative diseases is high. For this reason, the identification of relevant early molecular biomarkers is of paramount importance to allow an accurate diagnosis of the disease. 
Extracellular vesicles (EVs) are nanoparticles that are released in systemic circulation by most cell types. Their role in cell-to-cell communication has been widely documented and they have been implicated in several pathological conditions, including neurodegenerative diseases $(4,5)$. Three main EV types have been characterized according to their biogenesis: Apoptotic bodies, microvesicles and exosomes. However, the most recent guidelines highlight that these traditional definitions do not take into account the overlapping size range, similar morphology and variable composition of such EV subpopulations. Thus, a more appropriate nomenclature is emerging in literature, based on the classification of EVs by multiple parameters, such as size, density, protein composition, lipid content, RNA and DNA cargo, morphology, description of conditions and cell origin (6). EVs are stable and easily detectable in different body fluids and their content has become of interest for the development of EV-based molecular biomarkers for neurodegenerative diseases, including PD (7). Indeed, EV cargo is characterized by a repertoire of molecules that can be precisely isolated and their alteration may be associated with disease development and progression.

MicroRNAs (miRNAs) are members of EV cargo molecules and are small RNA molecules (18-22 nt) that mainly act as negative regulators of gene expression. They generally target the 3'UTR of mRNA by inducing the block of translation or its degradation. miRNAs are present in high amounts in EVs and different miRNA profiles in exosomes have been associated with pathological conditions. Gui et al developed a miRNA profiling strategy for exosomal miRNAs isolated from cerebrospinal fluid (CSF) of patients with PD (8). Exosomes were isolated from CSF using an ultracentrifugation method and, among the miRNA examined, miR-1 and miR-19b-3p were downregulated; while miR-153, miR-409-3p, miR-10a-5p and let-7g-3p were overexpressed in PD CSF exosomes. In recent studies, Cao et al and Yao et al reported a differential expression of given miRs in exosomes isolated by a commercial kit from the serum and plasma, respectively, of PD patients versus healthy individuals. Cao et al reported the downregulation of miR-19b and the overexpression of miR-195 and miR-24 (9), while Yao et al showed the differential expression of miR-331-5p and miR-505 (10).

Generally, many studies highlighted the different levels of selected miRNAs present in EVs indicating their role as possible molecular biomarkers. However, technical issues, including different protocols for $\mathrm{EV}$ isolation and optimization of methodologies to characterize profiles with low quantities of RNA, often make the characterization of the EV-RNA content inconsistent. According to the ISEV position article on the necessity of dealing with these issues (11), the current study was conducted to test the expression level of miR-34a-5p, not only in the whole plasma, but also in all the EV subpopulations of PD patients and control subjects to verify the contention that this strategy may be used to examine possible expression variations between PD and control subjects. To carry out this study, the strategy to isolate and characterize the different EV subpopulations using a standardized methodology (serial ultracentrifugations followed by density gradient) was employed. miR-34a-5p was selected because of its involvement in neurophysiology and neuropathology (12). miR-34a-5p is abundantly expressed in the adult mammalian brain and there is emerging evidence that miR-34a-5p plays key roles in mammalian neurogenesis, synaptogenesis and neural differentiation. Furthermore, miR-34a-5p has been recently described as a common dysregulated miRNA in different disorders of the central nervous system, including Alzheimer's disease, schizophrenia and major depression disorder (13).

In the current study, to the best of our knowledge, for the first time the expression levels of miR-34a-5p in whole plasma and in its different EV subpopulations (Large, LEVs; Medium, MEVs; Small EVs, SEVs; pure SEVs) isolated from PD patients and control subjects were examined.

\section{Materials and methods}

Clinicopathological features of subjects enrolled in this study. Peripheral blood was obtained from PD patients $(\mathrm{n}=15$; Neurology Unit, Civil Hospitals of Brescia, Italy) and control subjects ( $\mathrm{n}=14$; Geriatrics Unit, Civil Hospitals of Brescia, Italy). The study was approved by the ethics committee of Civil Hospitals of Brescia on 8th June 2016. Informed consent was obtained from all the subjects enrolled in the study.

The PD patients were male, with an age range of 70-92 years. Control subjects were age- and sex-matched to PD patients and they had no evidence of PD, parkinsonism or dementia. Clinical characteristics are reported in Table I for controls and PD patients. Unified Parkinson's Disease Rating Scale (UPDRS) and modified Hoehn and Yahr scale were used to evaluate PD symptoms $(14,15)$. Beck Depression Inventory (BDI) was used for the evaluation of depression of PD patients. Conventional cut-off values used were: 0-9 for normal range, $10-18$ for mild to moderate depression, 19-29 for moderate to severe depression, and 30-63 for severe depression (16).

Plasma pre-analytical processing. Plasma is the most suitable medium to extract blood physiological EVs because their total amount is not influenced by platelet-derived EVs released upon clot formation. We used samples containing EDTA, avoiding heparin based anticoagulants that may interfere further analyses $(17,18)$. Blood samples were processed within $2 \mathrm{~h}$ from the withdrawal and kept at room temperature. Careful tube transportation was ensured to avoid unnecessary agitation. For this purpose, a box maintaining blood tubes in a steady vertical position was used. Plasma-EDTA (plasma) was centrifuged at $800 \mathrm{x} \mathrm{g}$ for $10 \mathrm{~min}$ (5804R Eppendorf Centrifuge, A-4-44 rotor, $15 \mathrm{ml}$ tubes), 2,500 x g for $15 \mathrm{~min}$ and then centrifuged a second time at 2,500 $\mathrm{xg}$ for $15 \mathrm{~min}$. All centrifugations steps were made at room temperature with low acceleration and avoiding application of the centrifuge brake. After each centrifugation plasma was collected in a fresh plastic tube, leaving $1 \mathrm{~cm}$ of plasma above the buffy layer so as not to disturb it (19). Plasma was finally transferred into crio-vials in $1 \mathrm{ml}$ aliquots and stored at $-80^{\circ} \mathrm{C}$.

EV preparations from plasma of controls and PD subjects. All relevant data of the experiments have been submitted to the EV-TRACK knowledge base (EV-TRACK ID: EV200031) (20). Serial ultracentrifugation steps were: For each subject 4 vials of $1 \mathrm{ml}$ each of plasma were thawed and pooled. Pooled plasma $(3 \mathrm{ml})$ was then aliquoted in 3 Eppendorf tubes, $1 \mathrm{ml}$ each. One tube of $1 \mathrm{ml}$ aliquot was left at $4^{\circ} \mathrm{C}$ until further processing. 
Table I. Clinical features of subjects enrolled in this study.

\begin{tabular}{lcc}
\hline Parameters & Controls & PD patients \\
\hline No. of subjects enrolled & 14 & 15 \\
Sex & & \\
Male & 14 & 15 \\
Female & 0 & 0 \\
Age, years & $78.5 \pm 7.3$ & $75.7 \pm 3.0$ \\
Age at onset, years & - & $69.5 \pm 4.4$ \\
Duration of disease, years & - & $5.1 \pm 2.9$ \\
H and Y stage & - & $2.2 \pm 0.6$ \\
UPDRS I & - & $10.5 \pm 3.2$ \\
UPDRS II & - & $7.3 \pm 6.3$ \\
UPDRS III & - & $21.7 \pm 6.8$ \\
BDI score & - & $10.4 \pm 7.6$ \\
Levodopa dose, mg/day & - & $312.5 \pm 236.6$ \\
\hline
\end{tabular}

Data are expressed as mean $\pm \mathrm{SD} . \mathrm{H}$ and $\mathrm{Y}$, Hoehn and Yahr stage. UPDRS, unified Parkinson's disease rating scale. BDI, Beck Depression Inventory.

Two tubes of $1 \mathrm{ml}$ aliquot were processed, in parallel, with serial centrifugation steps as previously described (21). Briefly, $1 \mathrm{ml}$ plasma was centrifuged at $800 \mathrm{x}$ g for $30 \mathrm{~min}(5417 \mathrm{C}$ Eppendorf Centrifuge, 45-30-11 rotor, $1.5 \mathrm{ml}$ Eppendorf tubes, $1 \mathrm{ml}$ each tube). Supernatant $(1 \mathrm{ml})$ was transferred to a new tube and centrifuged at $16,000 \mathrm{x}$ g for $45 \mathrm{~min}(5417 \mathrm{C}$ Eppendorf Centrifuge, 45-30-11 rotor, $1.5 \mathrm{ml}$ Eppendorf tubes, $1 \mathrm{ml}$ each tube). Finally, supernatant $(1 \mathrm{ml})$ was transferred to an appropriate tube and centrifuged at $100,000 \times \mathrm{g}$ for $2 \mathrm{~h}$ (Optima MAX, TLA-55 rotor, $1.5 \mathrm{ml}$ polypropylene microfuge tube, Beckman). The $800 \mathrm{x}$ g centrifugation step allows sedimentation of LEVs, the $16,000 \times \mathrm{g}$ step allows us to pellet MEVs, while the $100,000 \times \mathrm{g}$ ultracentrifugation enriches SEVs. Pellets were washed with $1 \mathrm{ml}$ sterile $\mathrm{H}_{2} \mathrm{O}$ (Milli-Q, Merck Millipore) as described in Paolini et al (6).

Discontinuous sucrose gradient was carried out as follows: SEV pellet, obtained as described above, was further processed adapting the protocols developed in previous studies $(22,23)$ to obtain pure SEVs. Briefly, SEVs were re-suspended in 1,000 $\mu \mathrm{l}$ buffer A (10 mM Tris-HCl 250 mM sucrose, $\mathrm{pH} 7.4)$, loaded on top of a discontinuous sucrose gradient $15 \%$ (600 $\mu \mathrm{l}), 20$, $25,30,40,60 \%(400 \mu \mathrm{l}), 70 \%(800 \mu \mathrm{l})$ sucrose in $10 \mathrm{mM}$ Tris-HCl, pH 7.4) and centrifuged at 100,000 x g for $16 \mathrm{~h}$ at $4^{\circ} \mathrm{C}$ (rotor MLS 50; Beckman Optima MAX). Twelve fractions with equal volumes $(400 \mu \mathrm{l})$ were collected from the top of the gradient and ultracentrifuged $\left(100,000 \mathrm{x} \mathrm{g}\right.$ for $2 \mathrm{~h}$ at $\left.4^{\circ} \mathrm{C}\right)$. Western blot analysis fractions were precipitated by incubation with $10 \%$ trichloracetic acid (TCA) (Sigma) overnight as described in Paolini et al (24).

For RNaseA treatment (6.25 $\mu \mathrm{g} / \mathrm{ml}$; Qiagen), pure SEVs were resuspended in PBS. The RNase-treated samples were incubated at room temperature for $30 \mathrm{~min}$, followed by an inactivation step in ice for $1 \mathrm{~min}$; the non-treated samples were kept in ice. Total RNA was immediately isolated from the two samples and miR-34a-5p levels were analyzed as described below. No difference in miR-34a-5p levels was detected between the treated and non-treated pure SEVs indicating that miR-34a-5p is contained in vesicles (data not shown).

SDS-PAGE and western blot analysis. SDS-PAGE and western blotting (WB) were performed by standard procedures on the plasma EDTA samples (30 $\mu \mathrm{g}$, protein content determined by Bradford assay) (25), the LEV, MEV and SEV pellets and the gradient fractions positive to EV markers (from 5 to 9, collected together, nominated Pure SEV). LEV, MEV, SEV pellets and gradient fractions were resuspended in $50 \mu 1$ sterile $\mathrm{H}_{2} \mathrm{O}$ (Milli-Q, Merck Millipore). Ten $\mu \mathrm{l}$ of reducing sample buffer (480 mM Tris pH 6.8, 12\% SDS, 45\% glycerin, $0,06 \%$ bromophenol blue and $12 \%$ of $\beta$-mercaptoethanol) were added to samples and they were boiled for $5 \mathrm{~min}$ at $95^{\circ} \mathrm{C}$. Then, $20 \mu \mathrm{l}$ of each sample were electrophoresed, transferred to membrane and developed with antibodies. The following antibodies (1:500 dilution) were used to characterize EVs (26,27): mouse anti-Flotillin 1 (Santa Cruz Biotechnology, clone C-2, sc-74566), mouse anti-Annexin V (Santa-Cruz Biotechnology, clone H-3, sc-74438), rabbit anti-ADAM10 (Origene, AP05830PU-N), mouse anti-CD81 (Santa Cruz Biotechnology, clone B11, sc-166029), mouse anti-CD63 (Millipore, clone RFAC4, CBL553), mouse anti-Alix (Santa Cruz Biotechnology, clone 2H12, sc-53539), mouse anti TSG101 (Santa Cruz Biotechnology, clone C-2, sc-7964), rabbit anti-Actinin-4 (Genetex, clone N2C1, GTX113115). Mouse anti-GM130 Cis-Golgi protein diluted 1:250 (BD Transduction, clone 35/130, 610822) and rabbit anti-APOA1 diluted at 1:700 (Thermo Scientific Fisher, 701239) were used as negative controls.

Atomic force microscopy (AFM) imaging and size distribution. AFM imaging and image analysis were performed adapting protocols developed in previous studies (28-30). Briefly, the LEV, MEV and SEV pellets and the gradient fractions positive to EV markers (from 5 to 9, collected together and nominated Pure SEVs) were resuspended in $50 \mu$ l sterile $\mathrm{H}_{2} \mathrm{O}$ (Milli-Q; Merck Millipore) and diluted 1:10 in $\mathrm{H}_{2} \mathrm{O}$. Five $\mu \mathrm{l}$ of each sample were then spotted onto freshly cleaved mica sheets (Grade V-1, thickness $0.15 \mathrm{~mm}$, size 15x15 $\mathrm{mm}^{2}$ ) and the samples were allowed to dry at room temperature. They were imaged with a NaioAFM (Nanosurf AG) equipped with Multi75-AI-G tip (Budget Sensors). Images were acquired in tapping mode, with a scan size ranging from $1.5 \mu \mathrm{m}$ to $25 \mu \mathrm{m}$ and a scan speed of $1 \mathrm{sec}$ per scanning line. EV size distributions were obtained by image analysis of at least five representative AFM images with a scan size of $8.7 \times 8.7 \mu \mathrm{m}$. Image analysis was performed using WSxM version 5.0 and ImageJ (31).

EV subpopulations purity assessment. EV subpopulations were checked for purity from protein contaminants applying the COlorimetric NANoplasmonic (CONAN) assay, which exploits the nanoplasmonic properties of colloidal gold nanoparticles (AuNPs) and their peculiar interaction with proteins and lipid bilayers (32). LEV, MEV and SEV pellets and gradient fractions positive to EV markers (from 5 to 9, collected together; Pure SEV), were resuspended in $50 \mu \mathrm{l}$ of sterile $\mathrm{H}_{2} \mathrm{O}$ (Milli-Q; Merck Millipore). Then, $2 \mu \mathrm{l}$ of each sample were used for the assay. Three independent 
measurements of at least two representative subjects both for controls and PD patients were performed. The assay consisted of an aqueous solution of bare gold nanoparticles (AuNPs) at $6 \mathrm{nM}$ concentration. When mixed with pure EV formulations, the AuNPs clustered on the EV membrane, whereas in $\mathrm{EV}$ formulations which contained exogenous protein contaminants (EPCs) the AuNPs were preferentially cloaked by such EPCs (an AuNP-EPC corona forms), which prevents AuNPs from clustering to the EV membrane. When AuNPs cluster (are in tight proximity), their localized surface plasmon resonance (LSPR) red shifts and broadens, resulting in a color change of the AuNP solution from red to blue, which can be accurately monitored through UV-Vis spectroscopy. The assay red shift is therefore directly related to the purity grade of the added EV formulation and can be conveniently quantified by describing the AuNP UV/Vis/NIR absorption spectra with the nanoparticle Aggregation Index (AI), defined as the ratio between the absorbance intensity at the LSPR peak and the intensity at $650 \mathrm{~nm}$ plus the intensity at $850 \mathrm{~nm}$ (Abs LSPR/(Abs 650+Abs 850) (33).

Total RNA isolation. Total RNA was isolated from $200 \mu \mathrm{l}$ of plasma and each EV fraction using the miRNeasy mini kit (Qiagen). According to the manufacturers' protocol, plasma and EV pellets were lysed in $1 \mathrm{ml}$ of QIAzol. Then, $2.5 \mu \mathrm{l}$ of $5 \mathrm{nM}$ synthetic cel-miR-39 were added to each sample and $200 \mu \mathrm{l}$ of chloroform were used to separate the aqueous phase (34) including intellectual disability, congenital heart disease, childhood leukemia and immune defects. Specific microRNAs (miRNAs/miR. After centrifugation 12,000 x g for $15 \mathrm{~min}$ at $4^{\circ} \mathrm{C}$, the upper aqueous phase was transferred into a new tube and the miRNeasy kit protocol was followed. RNA was eluted in $35 \mu \mathrm{l}$ of RNase-free $\mathrm{H}_{2} \mathrm{O}$. The total RNA concentration was measured using a NanoDrop spectrophotometer (Thermo Fisher Scientific) and RNA quality was assessed using the 260/280 ratio. For RNA samples isolated from plasma and each EV type of a subgroup of random subjects (including controls and PD subjects), Agilent 2100 Bioanalyser using small RNA assay (Agilent) was used to analyze the concentration of small RNA and miRNA, miRNA percentage, and quality. This assay arbitrarily defined two distinct regions: Small RNA region from 0 to $150 \mathrm{nt}$ and miRNA region from 10 to $40 \mathrm{nt}$.

Bioinformatics analysis. The miRNA target genes were downloaded from miRWALK 3.0 (35) and the targets reported in the miRDB platform (781 genes) were selected for subsequent analysis. For functional enrichment analysis of gene ontology terms, Database for Annotation Visualization and Integrated Discovery (DAVID v6.8) was used (36,37). Kyoto Encyclopedia of Genes and Genomes (KEGG) pathway and Gene Ontology categories (Biological Process, Molecular Function and Cellular Component) were considered.

Quantitative PCR ( $q P C R$ ). Reverse transcription (RT) and qPCR were performed as previously described $(38,39)$. cDNA was synthesized from $5 \mu \mathrm{l}$ of RNA isolated from plasma or EV subpopulations using the TaqMan microRNA Reverse Transcription kit (Thermo Fisher Scientific) in a $15-\mu 1$ reaction containing $0.15 \mu \mathrm{l}$ of dNTPs, $1.00 \mu \mathrm{l}$ of $50 \mathrm{U} / \mu 1$ MultiScribe $^{\mathrm{TM}}$
Reverse Transcriptase, $1.50 \mu 1$ of $10 \mathrm{X}$ Reverse Transcription Buffer, $0.19 \mu \mathrm{l}$ of RNase Inhibitor, $4.16 \mu \mathrm{l}$ of nuclease-free water and $3 \mu \mathrm{l}$ of RT-specific stem-loop primers. The RT reaction was performed at $16^{\circ} \mathrm{C}$ for $30 \mathrm{~min}$, followed by incubation at $42^{\circ} \mathrm{C}$ for $30 \mathrm{~min}$ and $85^{\circ} \mathrm{C}$ for $5 \mathrm{~min}$. The qPCR reaction (20 $\mu \mathrm{l} /$ tube) contained $1.3 \mu \mathrm{l}$ of reverse transcription product, $10 \mu \mathrm{l}$ of Taq-Man 2X Universal PCR Master Mix and $1 \mu \mathrm{l}$ of the appropriate TaqMan MicroRNA Assay (20X) for miR-34a-5p (Thermo Fisher Scientific, assay ID 000426), miR-23b-3p (Thermo Fisher Scientific, assay ID 000400) and the spike-in cel-miR-39 (Thermo Fisher Scientific, assay ID 000200). The PCR reactions were incubated at $95^{\circ} \mathrm{C}$ for $10 \mathrm{~min}$, followed by 40 cycles at $95^{\circ} \mathrm{C}$ for $15 \mathrm{sec}$ and $60^{\circ} \mathrm{C}$ for $60 \mathrm{sec}$. PCRs were performed in triplicate using the 7500 real time PCR system (Applied Biosystems). Due to the lack of a known miRNA reference that would allow the normalization of circulating miRNAs, qPCR data were reported as the average raw cycle thresholds $(\mathrm{Ct})$ in both plasma and in the different EVs types.

Statistical analysis. Statistical analyses were performed using GraphPad Prism 6.01. Data are presented as average \pm SEM. The unpaired Student's t-test was used to determine whether the differences of miRNA expression between PD patients and controls were significant. Receiving operating characteristic (ROC) curve was conducted to assess the ability of pure SEVs miR-34a-5p to distinguish PD patients from controls. The differences in miR-34a-5p levels among PD patients groups with different disease severity were determined using one-way ANOVA followed by Bonferroni's test. The correlations between the miR-34a-5p levels in pure SEVs and clinical characteristics were assessed by Pearson's correlation test. Differences between groups were considered significant with P-value $\leq 0.05$.

\section{Results}

Different EV separation and characterization. We separated different subtypes of EVs from either control subjects or patients with Parkinson's disease via the serial ultracentrifugation protocol $\left(800 \mathrm{x}\right.$ g for $30 \mathrm{~min}$ at $4^{\circ} \mathrm{C}, 16,000 \mathrm{x} \mathrm{g}$ for $45 \mathrm{~min}$ at $4^{\circ} \mathrm{C}$ and $100,000 \times \mathrm{g}$ for $2 \mathrm{~h}$ at $4^{\circ} \mathrm{C}$ ) (Fig. 1A). This protocol allows the $\mathrm{EV}$ separation to be dependent on their different density and diameter. The $800 \mathrm{x}$ g centrifugation step allows sedimentation of cell debris and Large EVs (labelled LEVs), the $16,000 \mathrm{x}$ g step allows to pellet Medium EVs (labelled MEVs), while the final 100,000 x g ultracentrifugation (labelled SEVs) enriches Small EVs, exogenous protein contaminants (EPCs) and other nanoparticles that can co-precipitate after the last ultracentrifugation step. To further enrich small EVs, SEV pellet was loaded on top of a discontinuous sucrose gradient. Twelve fractions of equal volumes $(400 \mu \mathrm{l})$ were collected from the top after $16 \mathrm{~h}$ of ultracentrifugation at $100,000 \mathrm{x} \mathrm{g}$. For further analyses we selected fraction from 5 to 9, designated as pure SEVs, as described below.

Western blot (WB) analysis for different EV markers was performed on plasma and different preparations from either control subjects or PD patients in order to biochemically characterize them (Fig. 1B-D). Markers were chosen according to MISEV 2018 guidelines (40) and recent studies that compared the protein composition of different EV subtypes from 
A

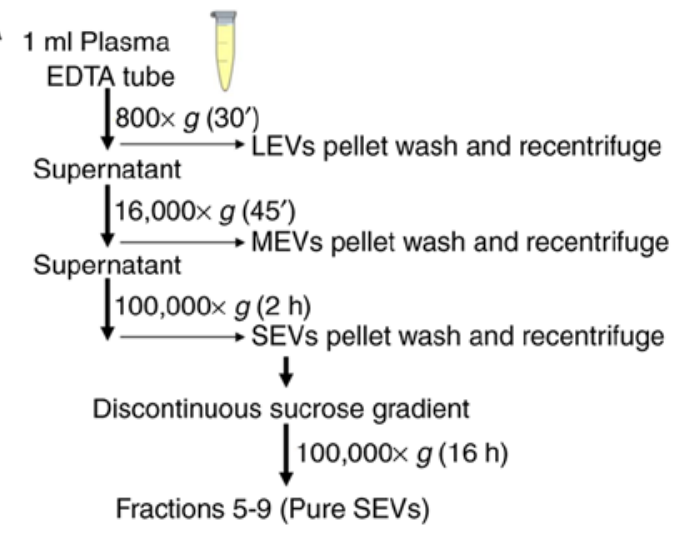
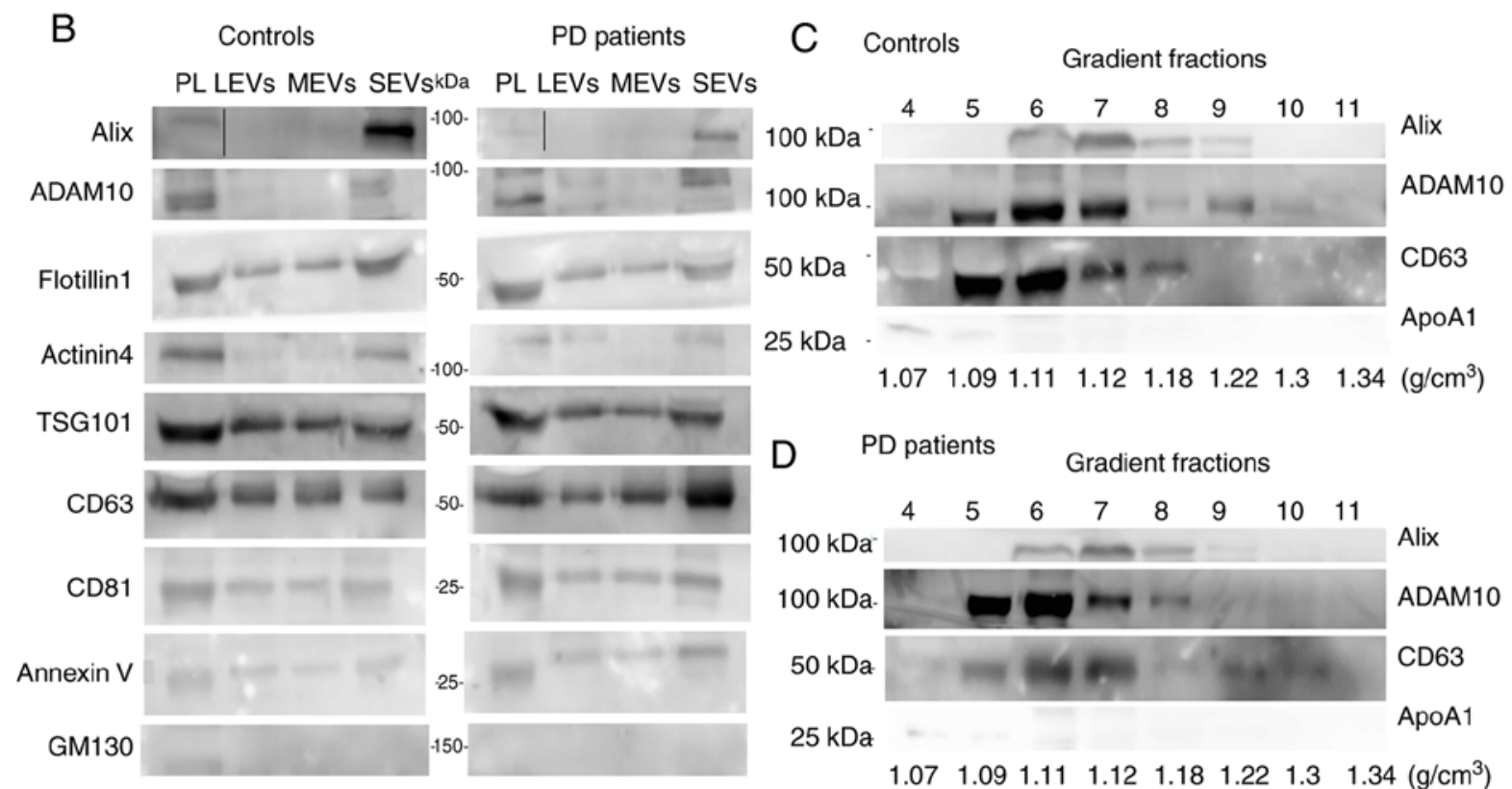

Figure 1. Biochemical characterization of EVs by western blot analysis. (A) Scheme of the serial ultracentrifugation protocol used to isolate the different EV subtypes. (B) Plasma (PL, $30 \mu \mathrm{g}$ ), EVs pelleted at $800 \mathrm{x}$ g for $30 \mathrm{~min}$ (LEVs), EVs pelleted at 16,000 x g for $45 \mathrm{~min}$ (MEVs), EVs pelleted at 100,000 x g for $2 \mathrm{~h}$ (SEVs) preparations $(20 \mu \mathrm{l})$ both from controls and PD patients were loaded. Gradient fractions from either controls (C) or PD patients (D) obtained with discontinuous sucrose gradient. Top numbers refer to the corresponding gradient fraction. Bottom numbers refer to sucrose density $\left(\mathrm{g} / \mathrm{cm}^{3}\right)$ for each fraction. Samples were electrophoresed on SDS-PAGE gel and analyzed using the antibodies described in the figures. PL, plasma; LEVs, large extracellular vesicles; MEVs, medium extracellular vesicles; SEVs, small extracellular vesicles.

different cell lines $(26,27,40)$. In our experimental conditions and using plasma as biological fluid we found an enrichment of Alix (intracytoplasmatic protein, involved in the regulation of the endosomal trafficking), ADAM10 (membrane protein belonging to the family of matrix metalloproteinases involved in several biological events, from the release of specific proteins or their fragments to shedding through EVs) and Actinin-4 (major vault protein) only in SEV preparation. Flotillin-1 (protein involved in the vesicular trafficking), tumor susceptibility gene 101 protein (TSG101) (component of the ESCRT-I complex, a regulator of the vesicular trafficking process and exosome biogenesis), Annexin V (cytosolic protein with membrane binding ability) and the tetraspanins CD63, CD81, were detectable in all preparations, even if with different degrees of enrichment (Fig. 1B). The cis-Golgi marker GM130 was somewhat visible in total plasma only, indicating an undetectable presence of intracytoplasmic membranous components in all preparations (Fig. 1B). In addition, small EV markers (Alix, ADAM10 and CD63) were visualized by WB in gradient fractions from 5 to 9 (pure SEVs) $\left(1.09-1.22 \mathrm{~g} / \mathrm{cm}^{3}\right.$ ) either in controls (Fig. 1C) or PD patients (Fig. 1D). The lipoprotein marker APOA1 was detectable in fraction 4 and 5 confirming that, using our separation protocol, most of the HDLs do not co-purify with pure SEVs.

EV preparations were analyzed by dry atomic force microscopy (AFM) to check the morphology and differences in size among LEVs, MEVs, SEVs and pure SEVs. All the preparations analyzed were composed of round-shaped objects and the size distribution for each preparation was estimated (Fig. 2A). AFM analysis confirmed that our separation protocol enriched EVs with different diameter distributions in both control and PD subjects. Enriched-LEVs sample exhibited the largest diameter distribution from 200 to $600 \mathrm{~nm}$; MEVs from 50 to $400 \mathrm{~nm}$; SEVs from 30 to $200 \mathrm{~nm}$, pure SEVs from 50 to $100 \mathrm{~nm}$ (Fig. 2B). Purity from protein contaminants was checked with the colorimetric nanoplasmonic (CONAN) assay (Fig. 3). For LEVs, MEVs and pure SEVs the mean AI values for both controls and PD patients, resulted in lower than 
A

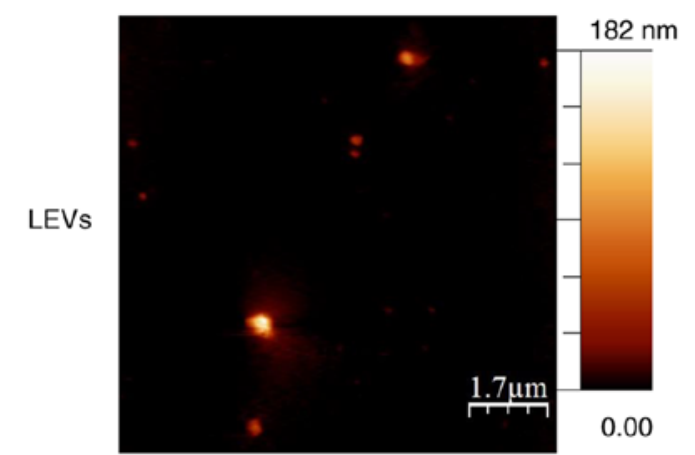

MEVS

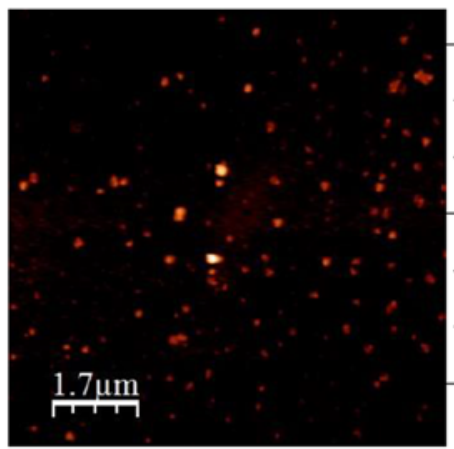

$106 \mathrm{~nm}$

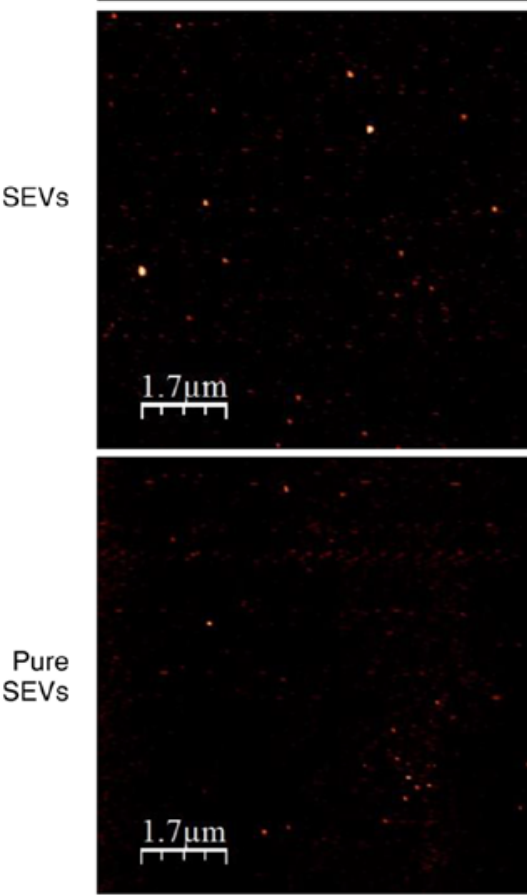

0.00

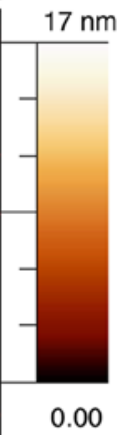

0.00

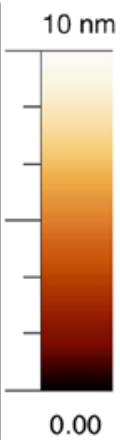

B

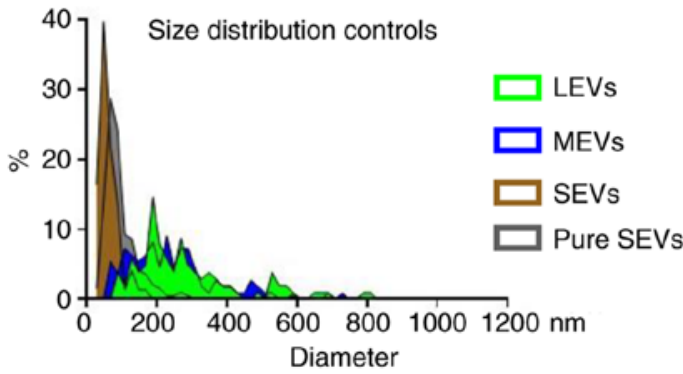

PD patients
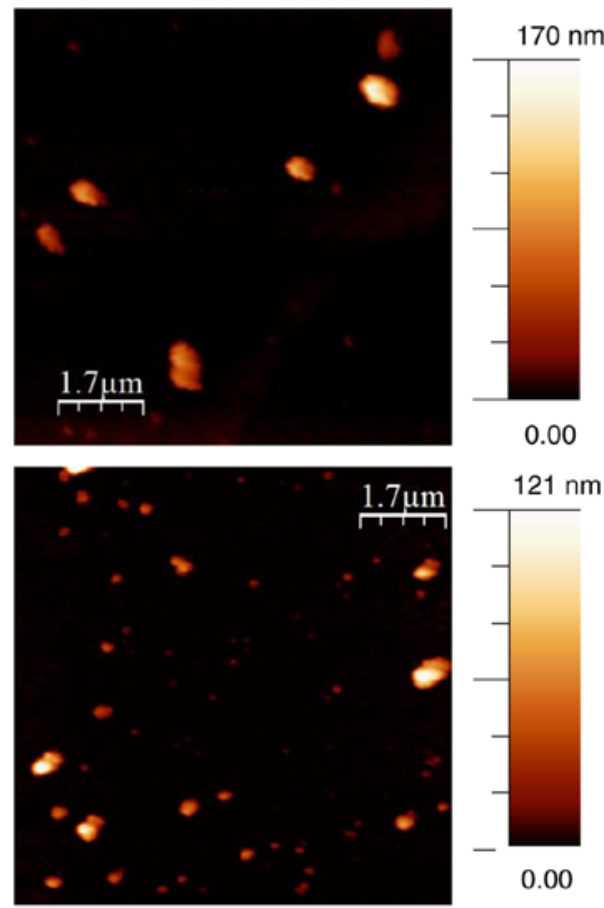

$121 \mathrm{~nm}$
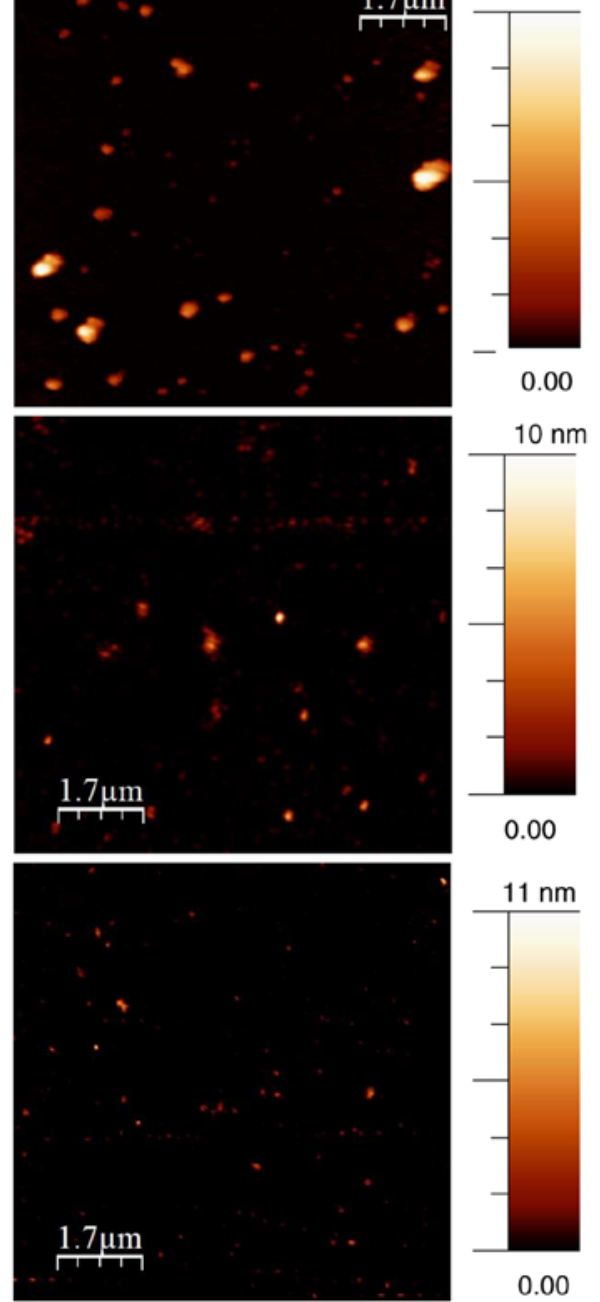

0.00

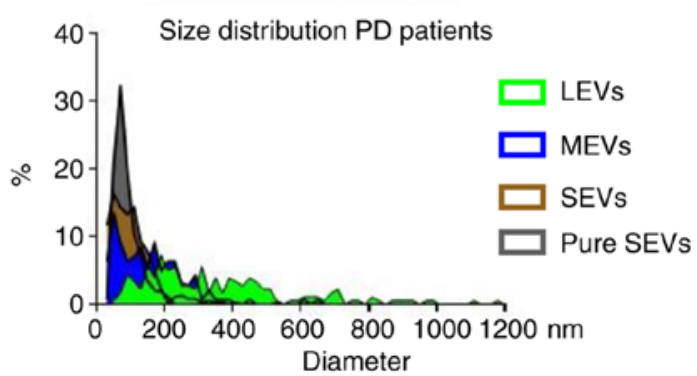

Figure 2. Imaging of different EV preparations. (A) Atomic force microscopy (AFM) topography image of the LEVs, MEVs, SEVs and gradient fractions positive to EV markers (from 5 to 9, pure SEVs), preparations from controls and PD patients. Samples were adsorbed onto mica sheets, as mentioned in Materials and methods section (scale bar is indicated in each image; colorimetric scale, on the right of AFM images, indicates the maximum height detected in each image). (B) Size distribution obtained from analysis of AFM images such as in (A) A total of $>500$ objects (both for controls and PD patients) were analyzed for LEVs (green), MEVs (blue), SEVs (brown) and pure SEVs (grey) fractions. Numbers on graphs indicate the diameter (in nm), of each preparation from controls and PD patients respectively. LEVs, large extracellular vesicles; MEVs, medium extracellular vesicles; SEVs, small extracellular vesicles. 


\section{A Controls}

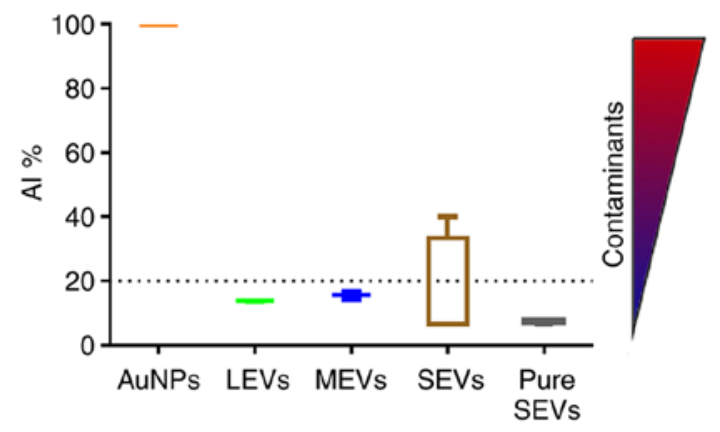

B

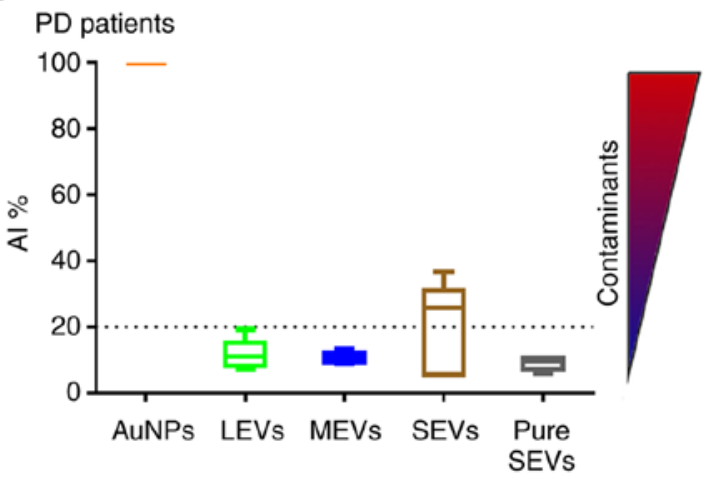

Figure 3. Determination of EV preparation purity from protein contaminants using CONAN assay. Normalized Aggregation Index (AI) of disperse gold nanoparticles (AuNPs), LEVs (green), MEVs (blue), SEVs (brown) and pure SEVs (grey) fractions are shown in the graph for either controls (A) and PD patients (B). AI decreases along with the change of the solution color from red to blue (as indicated by the color scale) and is inversely proportiona to the purity of preparation. Dotted line represents the $20 \%$ of AuNPs AI LEVs, large extracellular vesicles; MEVs, medium extracellular vesicles; SEVs, small extracellular vesicles.

$20 \%$ of the reference AI (i.e., the dispersed AuNPs solution, AI normalized at 100). This proves that the EV formulations contained negligible amounts of EPCs (33). However, SEV fraction returned a mean AI higher than $20 \%$, with high standard deviation, indicating that most of the SEV samples contain EPCs, even if in different amounts.

Small RNA profiles in plasma and EV fraction. To explore the profile of small RNA content in plasma and in different EV subpopulations, total RNA was isolated from $200 \mu \mathrm{l}$ of whole plasma and from the various EV fractions purified from $1 \mathrm{ml}$ of plasma. Small RNA and miRNA yield and miRNA percentage were detected in plasma and each fraction using Agilent 2100 Bioanalyser with small RNA assay. As shown in Table II, a different yield of small RNA and miRNA was obtained for the different samples indicating plasma as the sample with a minor content of small RNA, including miRNA, both in controls and in PD patients. In addition, $30 \%$ or more miRNA percentage was detected in plasma samples and all fractions from the two groups studied. Finally, the comparison among the different EV subpopulations showed that the miRNA yield (in ng) obtained from pure SEVs was greater than the one obtained from LEVs, MEVs or SEVs in the two groups. These data confirm that the small RNA cargo is different when different EV types are compared and highlight our protocol as a good standardized method to isolate miRNAs from the EV fractions.
Biological rationale for the selection of $m i R-34 a-5 p$ in the present study. In order to identify possible and relevant alterations of miRNA content in plasma and plasmatic EV subpopulations in PD, we selected miR-34a-5p due to its well-documented involvement in neurobiology. In Table III we summarized the biological processes modulated by miR-34a-5p in the nervous system. miR-34a-5p plays an important role in neurodevelopment by regulating different aspects of neurogenesis and synaptogenesis (41-44). In addition, miR-34a-5p is involved in neuronal differentiation and brain aging by targeting key genes, including cyclin D1, SIRT1, and Bcl-2 (45-50). Accordingly, the functional annotation analysis performed in the current study on the target genes of the miR-34a-5p using Database for Annotation Visualization and Integrated Discovery (DAVID v6.8) strongly supported the relevant role of miR-34a-5p in the nervous system (Fig. 4). In the cellular component category, 'Synapse' was the first term with 22 targets $(\mathrm{P}<0.05)$ and 'synaptic vesicle membrane', 'node of Ranvier', 'presynaptic membrane' and 'synaptobrevin 2-SN AP-25-syntaxin-1a-complexin II complex' were among the first 10 significant terms. For the biological process category, 'regulation of ion transmembrane transport' and 'regulation of calcium ion transport' were the third and eighth biological term, respectively. In the molecular function category, 414 predicted target genes were included in 'protein binding' term and the other enriched terms concerned to ion channels activity and transcription regulation. The KEGG pathway enrichment analysis outlined 51 biological terms $(\mathrm{P}<0.05)$. Among these, 'Cholinergic synapse', 'Dopaminergic synapse' and 'Synaptic vesicle cycle' represented the sixth, ninth and tenth biological term, respectively. The 'Cholinergic synapse' and 'Dopaminergic synapse' terms were both significantly enriched with 14 predicted genes and 'Synaptic vesicle cycle' with 9 predicted genes. Taken together, these data sustained the biological evidence to select this miRNA and to evaluate its levels in the whole plasma and its EV fractions in PD patients.

miR-34a-5p levels are higher in pure SEVs from PD patients compared to controls. As already mentioned, in this study we evaluated the level of miR-34a-5p in plasma and its EV fractions of PD patients. As shown in Fig. 5A, our findings revealed that miR-34a-5p was detectable in plasma, LEVs, MEVs, SEVs, but no differences in its levels were found between the two groups of subjects in these biological samples. Interestingly, the miR-34a-5p levels resulted in a significantly higher in the pure exosomes fraction from $\mathrm{PD}$ patients compared to controls (Fig. $5 \mathrm{~A}, \mathrm{Ct}_{\mathrm{PD}}$ average $=33.74$ versus $\mathrm{Ct}_{\mathrm{CONTROLS}}$ average=35.07; $\mathrm{P}<0.05)$. As mentioned in Materials and methods, the results of these experiments were reported as $\mathrm{Ct}$ average since no endogenous miRNAs were established as normalizers for plasma and the different EV fractions. Thus, in order to verify the good technical performance of RNA isolation, RT reaction and the specificity of observed changes in miR-34a-5p, we measured in the same samples the levels of the spike-in cel-miR-39 and has-miR-23b-3p, for which no roles in NCS have been reported yet. The $\mathrm{Ct}$ mean of each miRNA was nearly the same between PD patients and controls in plasma and in the EVs fractions (Fig. S1). The diagnostic significance of miR-34a-5p in pure SEVs was further tested by ROC curve analysis. The calculated Area under ROC curve (AUC) of 0.738 
Table II. Yield of small RNA and miRNA extracted from plasma and the different EV subpopulations derived from plasma of either controls or PD patients.

\begin{tabular}{lrrrrr}
\hline & \multicolumn{5}{c}{ Controls } \\
\cline { 2 - 6 } & Plasma & \multicolumn{1}{c}{ LEVs } & MEVs & \multicolumn{1}{c}{ SEVs } & Pure SEVs \\
\hline Small RNA (ng) & $2.26 \pm 1.27$ & $4.32 \pm 1.04$ & $4.90 \pm 0.95$ & $10.34 \pm 3.51$ & $14.51 \pm 8.03$ \\
miRNA (ng) & $0.82 \pm 0.49$ & $1.70 \pm 0.45$ & $2.12 \pm 0.26$ & $4.16 \pm 1.17$ & $9.87 \pm 6.72$ \\
miRNA/small RNA (\%) & $29.67 \pm 5.90$ & $37.07 \pm 3.45$ & $39.27 \pm 1.83$ & $39.43 \pm 1.82$ & $51.37 \pm 12.64$ \\
\hline & & \multicolumn{2}{c}{ PD patients } & & Pure SEVs \\
\cline { 2 - 6 } & Plasma & LEVs & MEVs & SEVs & $19.51 \pm 4.10$ \\
& $8.37 \pm 4.32$ & $13.15 \pm 2.15$ & $16.18 \pm 3.94$ & $11.76 \pm 3.94$ & $8.92 \pm 2.40$ \\
Small RNA (ng) & $4.03 \pm 2.14$ & $5.38 \pm 0.96$ & $7.00 \pm 1.48$ & $4.74 \pm 1.48$ & $35.15 \pm 0.35$ \\
miRNA (ng) & $32.80 \pm 2.40$ & $35.15 \pm 0.25$ & $36.50 \pm 0.60$ & $35.30 \pm 0.60$ & \\
miRNA/small RNA (\%) & &
\end{tabular}

Values are mean \pm SEM, $n=3$ for controls and $n=2$ for PD patients. Yield of small RNA and miRNA is calculated starting from the concentration (ng/ $\mu \mathrm{l}$ ) determined by the Small RNA Assay (Agilent). LEVs, large extracellular vesicles; MEVs, medium extracellular vesicles; SEVs, small extracellular vesicles.

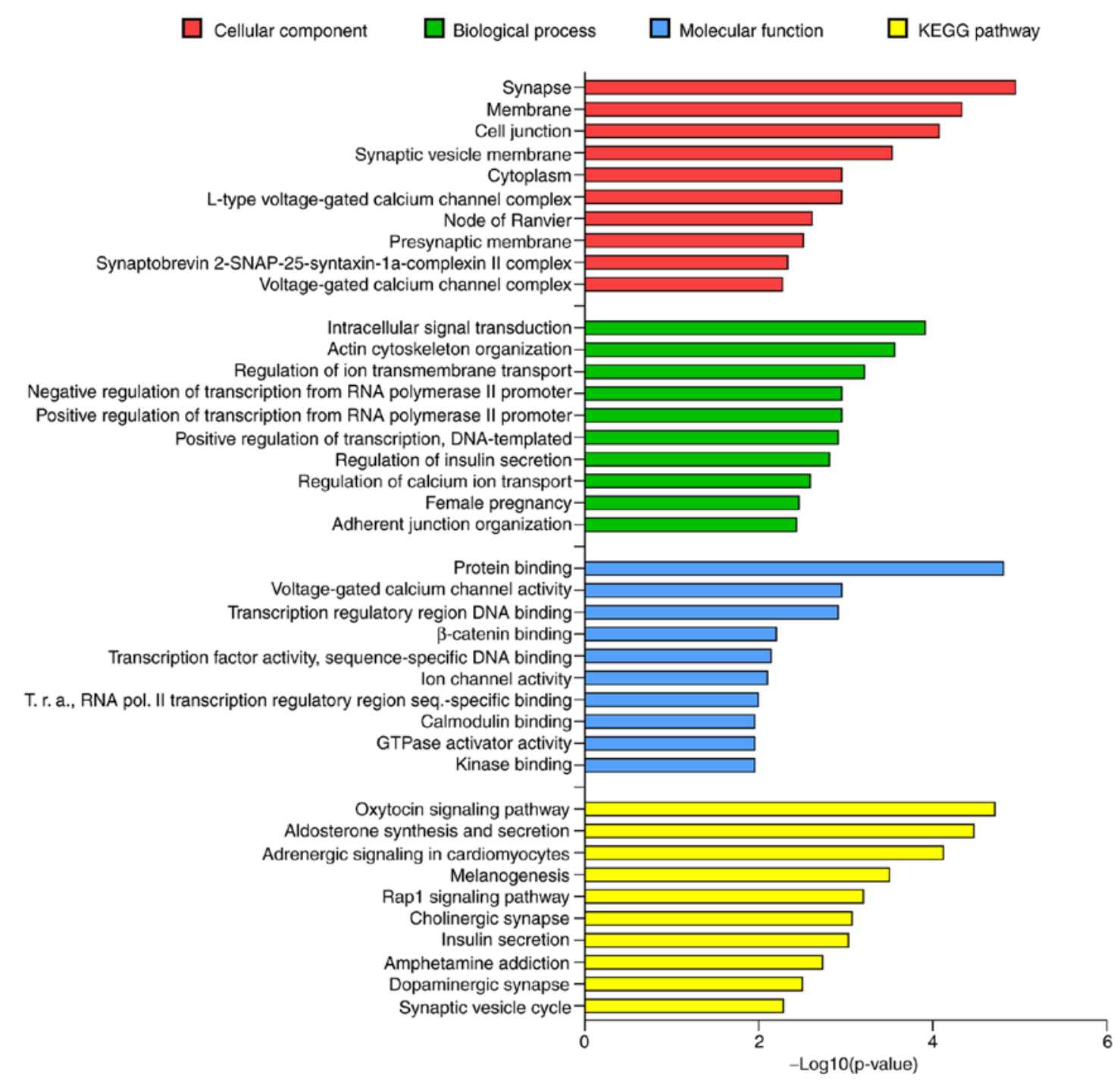

Figure 4. Gene Ontology Top 10 significant terms belonging to the cellular component (red), biological process (green), molecular function (blue) categories and KEGG pathways (yellow). The GO terms reported in bold are related to nervous system. T.r.a., Transcription repressor activity. 
Table III. Biological processes modulated by miR-34a-5p in the nervous system.

Neurological

process Molecular mechanism mediated by miR-34a-5p

Experimental model

(Refs.)

\begin{tabular}{|c|c|c|}
\hline Neurogenesis & $\begin{array}{l}\text { Regulation of proliferation in neural progenitors. } \\
\text { Modulation of morphology and electrophysiological } \\
\text { properties in differentiating neurons. }\end{array}$ & Rat CN, rAAV-miR \\
\hline Synaptogenesis & $\begin{array}{l}\text { Negative regulation of the synaptic targets SYT-1 and } \\
\text { STX1A. } \\
\text { Modulation of the expression of the presynaptic and } \\
\text { postsynaptic neuronal markers, including SYP and SYN1. } \\
\text { Alteration of neurite outgrowth and spinal morphology. }\end{array}$ & $\begin{array}{l}\text { Mouse CN Mouse NS } \\
\text { Human iPSC-derived }\end{array}$ \\
\hline $\begin{array}{l}\text { Neuronal } \\
\text { differentiation }\end{array}$ & $\begin{array}{l}\text { Suppression of cell cycle entry by targeting cyclin D1 in } \\
\text { mature neurons. } \\
\text { Influence of neuronal survival by the direct regulation } \\
\text { of the anti-apoptotic gene Bcl-2 and the protein deacetylase } \\
\text { SIRT-1 which has a neuroprotective activity. }\end{array}$ & $\begin{array}{l}\text { Rat CN SH-SY5Y cel } \\
\text { APPswe/PSE9 mouse } \\
\text { Mouse NSC }\end{array}$ \\
\hline $\begin{array}{l}\text { Cognitive } \\
\text { functions }\end{array}$ & $\begin{array}{l}\text { Impairment of cued fear memory consolidation through } \\
\text { the modulation of Notch pathway in the basolateral } \\
\text { amygdala. } \\
\text { Alteration of learning abilities and emotionality in rats. }\end{array}$ & $\begin{array}{l}\text { miR-34a sponge-infu } \\
\text { rAAV-miR-34a-infus }\end{array}$ \\
\hline Brain aging & $\begin{array}{l}\text { Modulation of neural deterioration with age and alteration } \\
\text { of aging-associated transcriptional profile. Support of healthy } \\
\text { brain aging through the inhibition of PRC } 2 \text { and the decrease } \\
\text { of } \mathrm{H} 3 \mathrm{~K} 27 \mathrm{me} 3 \text { that determines the reduction of small heat } \\
\text { shock proteins. }\end{array}$ & miR-34-/-Drosophila \\
\hline
\end{tabular}

Modulation of morphology and electrophysiological

Negative regulation of the synaptic targets SYT-1 and

Mouse CN Mouse NSC

Modulation of the expression of the presynaptic and

postsynaptic neuronal markers, including SYP and SYN1.

Suppression of cell cycle entry by targeting cyclin D1 in ture neurons.

Influence of neuronal survival by the direct regulation

APPswe/PSE9 mouse

SIRT-1 which has a neuroprotective activity.
Cognitive Impairment of cued fear memory consolidation through the modulation of Notch pathway in the basolateral amygdala. of aging-associated transcriptional profile. Support of healthy brain aging through the inhibition of PRC 2 and the decrease shock proteins.

CN, cortical neurons; rAAV, recombinant adenoassociated virus; SYT-1, Synaptotagmin-1; STX1A, Syntaxin-1A; SYP, synaptophysin; SYN1, Synapsin 1; NSC, neural stem cells; iPSC, induced pluripotent stem cells; PRC2, Polycomb Repressive Complex 2; H3K27me3, tri-methylation of lysine 27 of histone 3 .

(95\% CI=0.557-0.919; $\mathrm{P}<0.05)$ may indicate that the levels of this miRNA in pure SEVs may discriminate controls from PD patients with good accuracy in the examined cohort (Fig. 5B).

Correlations between pure SEVs miR-34a-5p levels and clinical parameters of $P D$ patients. We considered and explored whether miR-34a-5p levels detected in pure SEVs could be related to clinical parameters, including disease duration, the scores of clinical disease severity and depression, and levodopa dose. To carry out this analysis, the PD patients were divided into sub-groups according to disease duration and Hoehn\&Yahr grade. The miR-34a-5p mean Ct value was significantly lower in PD patients with shorter disease duration ( $\leq 5$ years; $\mathrm{P}<0.05$ ), with respect to control subjects. By considering the group of PD patients with disease duration $>5$ years, a trend of decrease of miR-34a-5p Ct values was found in respect to controls (not significant) (Fig. 6A). Interestingly, PD patients with higher Hoehn\&Yahr score $(\mathrm{H} \& \mathrm{Y}$ score $=3)$ showed a significant decrease of the miR-34a-5p mean $\mathrm{Ct}$ value compared to control subjects $(\mathrm{P}<0.05$; Fig. 6B). Moreover, the miR-34a-5p mean $\mathrm{Ct}$ value in plasmatic pure SEVs from PD patients resulted correlated positively with Beck Depression Inventory (BDI) score $(\mathrm{P}<0.05$; Fig. 6C). However, no significant correlation was found with age at onset, Levodopa dose, and unified Parkinson's disease rating scale (UPDRS) in PD patients (Fig. S2).

\section{Discussion}

Circulating Extracellular Vesicles (EVs) containing disease-specific molecular signatures (including miRNAs) have recently emerged as promising biomarkers in neurodegenerative diseases. Circulating microRNAs encapsulated in EVs remain stable in body fluids and are easily detected using standard molecular techniques, such as RT-qPCR, allowing the identification of specific circulating miRNAs that are differentially expressed between patients and control subjects (51).

For Parkinson's disease very few data have been reported concerning the detection of miRNAs within EVs and their potential role as biomarkers $(52,53)$. Moreover, no study has taken into consideration the miRNAs content in all the different vesicle types isolated from plasma/serum or cerebrospinal fluid of PD patients. To the best of our knowledge, this is the first study that used differential centrifugation followed by density gradient to isolate all the EVs fractions from the plasma of PD patients, including LEVs, MEVs, SEVs and pure SEVs. Regarding the RNA content of EVs, it has been known that different RNA profiles are detectable in the different subpopulations of EVs. The collective data from the few published studies on this topic indicate that the exosomes released by different cell lines carry a significant amount of small RNAs 


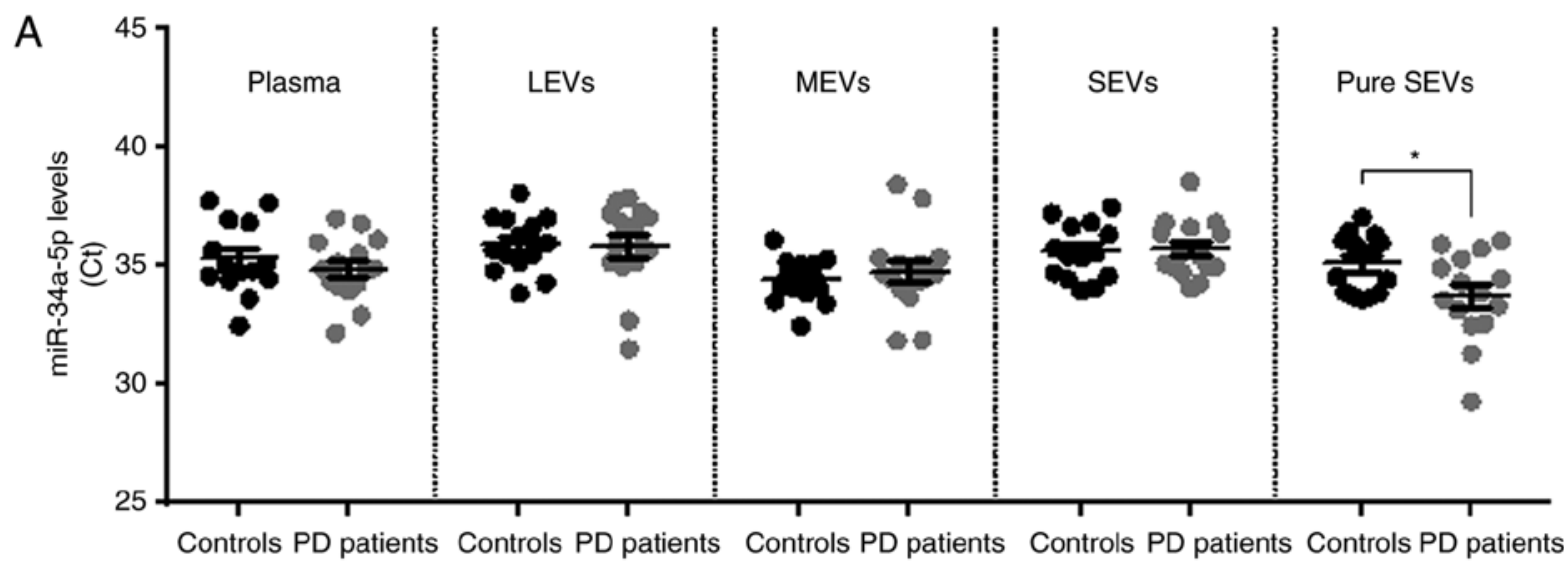

B

ROC for miR-34a-5p in Pure SEVs

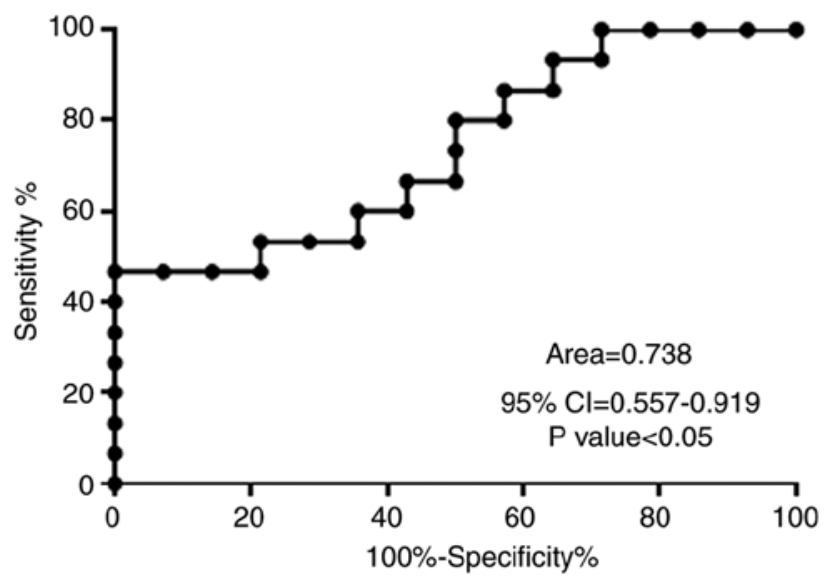

Figure 5. Levels of miR-34a-5p in plasma and different EV types from either control subjects or PD patients. (A) Dot-plots show the miR-34a-5p Ct values determined by qPCR in plasma and plasmatic EVs for each subject $\left(n_{\text {controls }}=14 ; n_{\text {PD patients }}=15\right)$; each dot represents a sample while largest bar represents the average \pm SEM. miR-34a-5p levels were significantly higher in pure SEVs of PD patients compared to controls; "P $<0.05$ using unpaired t-test analysis. No significant differences were observed for plasma and in the other types of EVs. (B) ROC analysis for the ability of miR-34a-5p levels in pure SEVs to discriminate between control individuals and PD patients. LEVs, large extracellular vesicles; MEVs, medium extracellular vesicles; SEVs, small extracellular vesicles.

respect to apoptotic bodies and microvesicles. On the other hand, these fractions contain ribosomal RNA (displayed as two peaks corresponding to subunits $18 \mathrm{~S}$ and $28 \mathrm{~S}$ in RNA profiles) that is totally absent in exosomes (54,55). In agreement with this, in the present study, the small RNA profiles obtained from plasmatic EVs of controls and PD subjects showed that the pure SEVs contained relatively more miRNAs than the other fractions tested in this study. In addition, the miRNAs yield in pure SEVs was similar between controls and patients groups and it could be considered a very appreciable quantity because it was higher than the range value of $1-10 \mathrm{ng} / \mathrm{ml}$ plasma of exosomal RNA yield obtained using spin column method (56), but also the mean yield reported by Lunavat et al for miRNAs from plasmatic exosomes isolated using ultracentrifugation or commercial kits (55). The results shown in the present study proved that the experimental workflow used is a reliable method to isolate EV-associated miRNAs, i.e., the SEV miRNAs, from plasma also supporting its potential use for the preparation of the small non-coding RNA samples for the discovery of biomarkers of a given disease.

In the current study, the levels of circulating miR-34a-5p were evaluated to identify possible alterations between plasma and plasmatic EV subpopulations in PD patients and between patients and control subjects. In this context, various strategies have been used to select the miRNAs to be studied as circulating molecules in PD patients (57). In the current study, the selection of miR-34a-5p was based on its fundamental role in the regulation of neuronal gene expression and its important functions in the central nervous system, as summarized in Table III. In addition, our data derived from the functional annotation analysis of miR-34a-5p predicting target genes strongly supported the important functions of this miRNA in pathways and biological structures clearly associated to the nervous system. It is known that miR-34a-5p is abundantly expressed in the adult brain as indicated by miRNAs expression profiling studies in rodents $(58,59)$. and its expression level in neurons needs to be finely regulated to allow proper neuronal development and aging.

Regarding the role of miR-34a-5p in neuropathology, several in vitro and in vivo studies have linked miR-34a-5p to neurodegenerative diseases. Expression of miR-34a-5p was elevated in the hippocampus and temporal cortex of $3 \times \mathrm{Tg}$ AD mice, a model of familial Alzheimer's disease (AD) (60). Moreover in the human brain, miR-34a-5p was upregulated in the hippocampal region of $\mathrm{AD}$ patients compared to controls (61). Regarding PD, no evidence has revealed any 

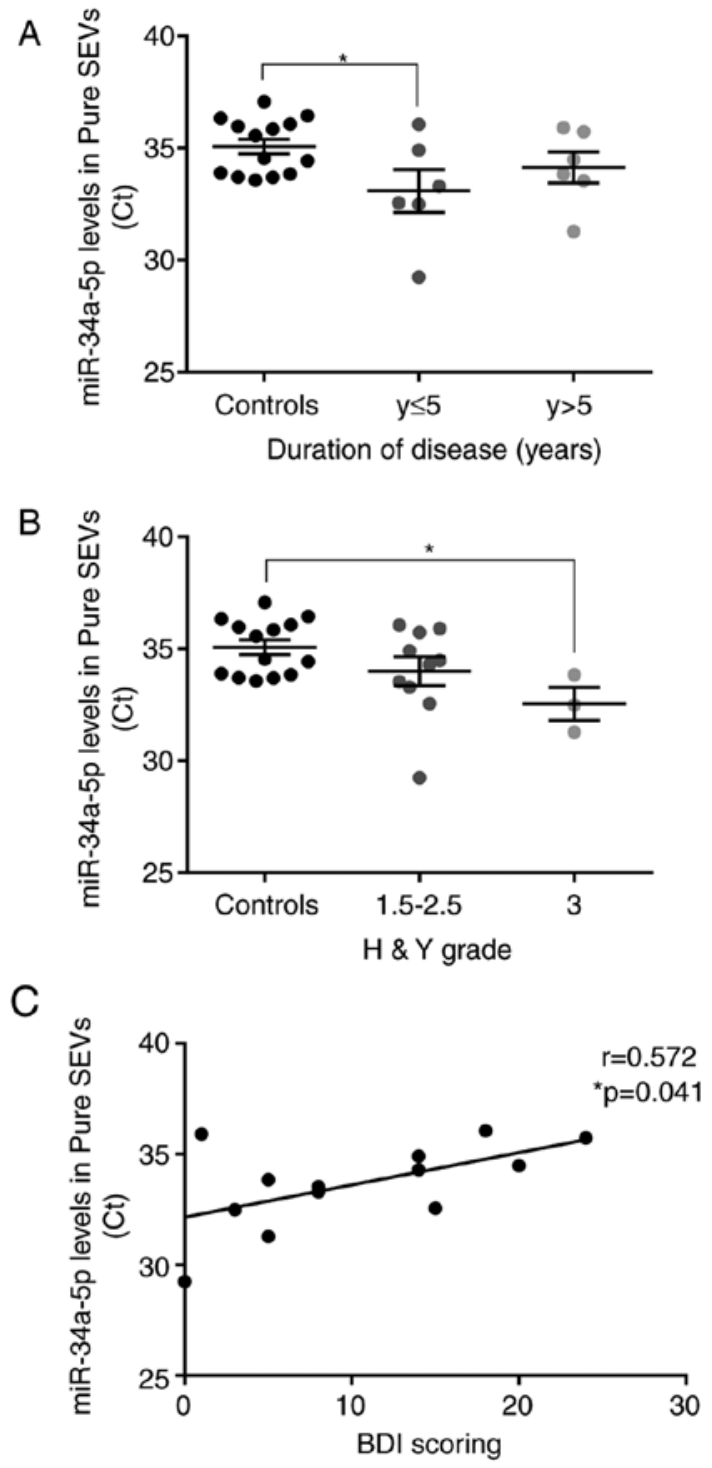

Figure 6. Correlation between the level of miR-34a-5p found in pure SEVs with clinical parameters of PD patients. (A) miR-34a-5p levels were significantly higher in pure SEVs of PD patients within five years from onset compared to controls. (B) miR-34a-5p was significantly upregulated in pure SEVs of PD patients with higher Hoer\&Yahr grade (H\&Y grade) compared to controls One-way ANOVA was used for multiple comparisons among groups followed by Bonferroni's test; ${ }^{*} \mathrm{P}<0.05$. (C) Positive correlation was found between $\mathrm{Ct}$ values for miR-34a-5p levels in plasmatic pure SEVs and Beck Depression Inventory (BDI) scoring of PD patients. Correlation was tested with Pearson's correlation analysis, ${ }^{*} \mathrm{P}<0.05$. Pure SEVs, pure small extracellular vesicles.

dysregulation of miR-34a-5p in the human brain thus far (62). However, some studies have reported the over-expression of miR-34a-5p both in in vitro and in vivo models of $\mathrm{PD}$, such as differentiated PC12 cells treated with the dopaminergic neurotoxin $\mathrm{MPP}^{+}$and rats chronically exposed to rotenone (63-65), respectively. In addition, the downregulation of miR-34a-5p induced by lithium or the use of anti-miR molecules improved cell survival and showed neuroprotective effects in neuronal cells treated with PD-associated neurotoxins (paraquat and rotenone) $(66,67)$.

In the current study, we showed that miR-34a-5p can be easily detected both in plasma, such as miRNA vesicle-free primarily, and in plasmatic EVs from control subjects and PD patients suggesting that this miRNA is secreted by cells and remains stable in circulation. In light of this, Cosín-Tomás et al reported that miR-34a-5p was downregulated in plasma of AD patients, but not in that of PD patients (68). Furthermore, the miR-34a-5p ectopic overexpression in primary cortical neurons revealed the secretion of miR-34a-5p containing exosomes that were taken up by neighboring cells as demonstrated using co-culture experiments (60). Mao et al showed that EVs from astrocytes contain increased miR-34a-5p after the stimulation of the stress condition induced by Lipopolysaccharide (LPS) (69). Of note, the secreted miR-34a-5p in astrocytic EVs enhanced the vulnerability of SH-SY5Y cells to neurotoxins exposure by inhibiting Bcl-2 expression. Blocking the upregulation of miR-34a-5p in LPS-stimulated astrocyte EVs alleviated the loss of dopaminergic neurons in vitro and in vivo (69). All these data seem to suggest that cell stress conditions or neurotoxic exposures increase the intracellular miR-34a-5p in specific brain regions. Moreover, the altered miR-34a-5p level can be delivered in EVs and then modulate some significant biological functions in the receiving cell in disease.

In the present study, for the first time, we found that miR-34a-5p levels were significantly overexpressed in pure SEVs from plasma of PD patients compared to controls and that its expression in pure SEVs revealed a good ability of this miRNA to distinguish PD patients from control subjects suggesting its potential consideration as a marker of diagnosis at molecular level. Moreover, pure SEVs miR-34a-5p levels were higher in PD patients even at the beginning stage of PD when the disease duration is less than 5 years. Finally, high levels of pure SEV miR-34a-5p were detected in PD patients with mild/progressive symptoms of disease and were associated with minimal/absent depression. In our opinion, the dysregulation of circulating miR-34a-5p depending on neuropathological conditions, such as depression, is not unexpected. Indeed, elevated levels of miR-34a-5p were found in serum of patients with major depressive disorders and in post-mortem cerebellar tissues and iPSC-derived neurons of bipolar disorder patients $(44,70)$. However, further studies are needed to clarify whether the analysis of circulating miR-34a-5p in the different biological samples may be useful for the identification of depressive states.

In conclusion, our data showed the differential expression between PD patients and control subjects of miR-34a-5p in plasmatic pure SEVs, but not in the other EV fractions, suggesting the necessity to consider not only the whole plasma, but each EV subpopulation in order to improve the possibility to identify relevant differences of specific miRNAs levels. For this purpose, the SEVs purification protocol is crucial since the presence of protein contaminants in the sample seems to conceal those differences (21). We have clearly defined this study as an exploratory one and further investigations are necessary to verify the potential diagnostic value of circulating miR-34a-5p in PD. Since our findings derive from an exploratory study, they trace the starting point for future research. Indeed, they address the direct use of pure SEVs: i) To detect the miR-34a-5p levels in larger cohorts that also include female PD patients allowing the reduction of the number of samples to be analysed; ii) To perform RNA-seq experiments in order to identify novel potential biomarkers among the entire repertoire of circulating miRNAs in PD patients. Finally, we think that the exploration on the origin of pure SEVs [i.e., 
from brain: neuron-, astrocyte- or oligodendrocyte-derived exosomes (71)], could be useful for the comprehension of the role of secreted miR-34a-5p in PD.

\section{Acknowledgements}

We would like to thank Dr M. Crosatti (University of Leicester; UK) for the linguistic revision of the manuscript.

\section{Funding}

This work was supported by a BIOMANE grant (University of Brescia, Brescia, Italy) to MP, GDP, AP and AM; by FFRB grants (Italian Ministry of University and Research) to AS and AR; by research local funds (University of Brescia) to GDP and AS; by a CIB grant (Biotechnology Inter-university Consortium) to GDP.

\section{Availability of data and materials}

All data generated or analyzed during this study are included in this published article.

\section{Authors' contributions}

GDP conceived this study. GDP, AS, AR, IG, LP designed the experimental workflow. APad, APil; and AM provided the clinical samples and the clinical characteristics of the enrolled subjects. VP performed the plasma-pre-analytical processing. $\mathrm{LP}$ and $\mathrm{AR}$ performed the EV characterization experiments of WB, AFM imaging and CONAN assay. IG performed the RNA isolation from plasma and each EV subpopulation, the qPCR experiments and the statistical analyses. AS performed the Small RNA assay using the Agilent 2100 Bioanalyser. IG and LP wrote the manuscript. All co-authors, IG, AR, LP, VP, APad, APil, AM, ABel, ABar, MP, AS and GDP, collaborated in the discussion of the data and in the critical revision of the manuscript. IG, AR, AS and GDP drafted the final version of the manuscript. All co-authors read and approved the final version of the manuscript.

\section{Ethics approval and consent to participate}

The study was approved by the ethics committee of Spedali Civili di Brescia on 8th June 2016. Informed consent was obtained from all the subjects enrolled in the study.

\section{Patient consent for publication}

Not applicable.

\section{Competing interests}

The authors declare no competing of interest.

\section{References}

1. Tysnes OB and Storstein A: Epidemiology of Parkinson's disease. J Neural Transm (Vienna) 12: 901-905, 2017.

2. Spillantini MG and Goedert M: Neurodegeneration and the ordered assembly of $\alpha$-synuclein. Cell Tissue Res 373: 137-148, 2018.
3. Bellucci A, Mercuri NB, Venneri A, Faustini G, Longhena F, Pizzi M, Missale C and Spano P: parkinson's disease: From synaptic loss to connectome dysfunction. Neuropathol Appl Neurobiol 42: 77-94, 2016.

4. Thompson AG, Gray E, Heman-Ackah SM, Mäger I, Talbot K, El Andaloussi S, Wood MJ and Turner MR: Extracellular vesicles in neurodegenerative disease-pathogenesis to biomarkers. Nat Rev Neurol 12: 346-357, 2016.

5. Tofaris GK: A critical assessment of exosomes in the pathogenesis and stratification of parkinson's disease. J Parkinsons Dis 7: 569-579, 2017.

6. Paolini L, Federici S, Consoli G, Arceri D, Radeghieri A, Alessandri I and Bergese P: Fourier-Transform infrared (FT-IR) spectroscopy fingerprints subpopulations of extracellular vesicles of different sizes and cellular origin. J Extracell Vesicles 9: $1741174,2020$.

7. Tomlinson PR, Zheng Y, Fischer R, Heidasch R, Gardiner C, Evetts S, Hu M, Wade-Martins R, Turner MR, Morris J, et al: Identification of distinct circulating exosomes in parkinson's disease. Ann Clin Transl Neurol 2: 353-361, 2015.

8. Gui YX, Liu H, Zhang LS, Lv W and Hu XY: Altered microRNA profiles in cerebrospinal fluid exosome in parkinson disease and alzheimer disease. Oncotarget 10: 37043-37053, 2015.

9. Cao XY, Lu JM, Zhao ZQ, Li MC, Lu T, An XS and Xue LJ: MicroRNA biomarkers of Parkinson's disease in serum exosome-like microvesicles. Neurosci Lett 644: 94-99, 2017.

10. Yao YF, Qu MW, Li GC, Zhang FB and Rui HC: Circulating exosomal miRNAs as diagnostic biomarkers in parkinson's disease. Eur Rev Med Pharmacol Sci 22: 5278-5283, 2018.

11. Mateescu B, Kowal EJ, van Balkom BW, Bartel S, Bhattacharyya SN, Buzás EI, Buck AH, de Candia P, Chow FW, Das S, et al: Obstacles and opportunities in the functional analysis of extracellular vesicle RNA-an ISEV position paper. J Extracell vesicles 6: 1286095, 2017.

12. Chua CE and Tan BL: MiR-34a in neurophysiology and neuropathology. J Mol Neurosci 67: 235-246, 2019.

13. van den Berg MM, Krauskopf J, Ramaekers JG, Kleinjans JC, Prickaerts J and Briedé JJ: Circulating microRNAs as potential biomarkers for psychiatric and neurodegenerative disorders. Prog Neurobiol 185: 101732, 2020.

14. Goetz CG, Fahn S, Martinez-Martin P, Poewe W, Sampaio C, Stebbins GT, Stern MB, Tilley BC, Dodel R, Dubois B, et al: Movement disorder society-sponsored revision of the unified parkinson's disease rating scale (MDS-UPDRS): Process, format, and clinimetric testing plan. Mov Disord 22: 41-47, 2007.

15. Goetz CG, Poewe W, Rascol O, Sampaio C, Stebbins GT, Counsell C, Giladi N, Holloway RG, Moore CG, Wenning GK, et al: Movement disorder society task force report on the hoehn and yahr staging scale: Status and recommendations. Mov Disord 19: 1020-1028, 2004.

16. Beck AT, Ward CH, Mendelson M, Mock J and Erbaugh J: An inventory for measuring depression. Arch Gen Psychiatry 4: 561-571, 1961.

17. Witwer KW, Buzás EI, Bemis LT, Bora A, Lässer C, Lötvall J, Nolte-'t Hoen EN, Piper MG, Sivaraman S, Skog J, et al: Standardization of sample collection, isolation and analysis methods in extracellular vesicle research. J Extracell Vesicles 2: $27,2013$.

18. Coumans FA, Brisson AR, Buzas EI, Dignat-George F, Drees EE, El-Andaloussi S, Emanueli C, Gasecka A, Hendrix A, Hill AF, et al: Methodological guidelines to study extracellular vesicles. Circ Res 120: 1632-1648, 2017.

19. Lacroix R, Judicone C, Mooberry M, Boucekine M, Key NS, Dignat-George F; The ISTH SSC Workshop: Standardization of pre-analytical variables in plasma microparticle determination: Results of the international society on thrombosis and haemostasis SSC collaborative workshop. J Thromb Haemost 11:. 1190, 2013.

20. Van Deun J, Mestdagh P, Agostinis P, Akay Ö, Anand S, Anckaert J, Martinez ZA, Baetens T, Beghein E, Bertier L, et al: EV-TRACK: Transparent reporting and centralizing knowledge in extracellular vesicle research. Nat Methods 28: 228-232, 2017.

21. Paolini L, Zendrini A, Di Noto G, Busatto S, Lottini E, Radeghieri A, Dossi A, Caneschi A, Ricotta D and Bergese P: Residual matrix from different separation techniques impacts exosome biological activity. Sci Rep 6: 23550, 2016.

22. Di Noto G, Chiarini M, Paolini LL, Mazzoldi EL, Giustini V, Radeghieri A, Caimi L and Ricotta D: Immunoglobulin free light chains and GAGs mediate multiple myeloma extracellular vesicles uptake and secondary $\mathrm{Nf} \kappa \mathrm{B}$ nuclear translocation. Front Immunol 5: 517, 2014. 
23. Di Noto G, Paolini L, Zendrini A, Radeghieri A, Caimi L and Ricotta D: C-Src enriched serum microvesicles are generated in malignant plasma cell dyscrasia. PLoS One 8: e70811, 2013.

24. Paolini L, Radeghieri A, Civini S, Caimi L and Ricotta D: The epsilon hinge-ear region regulates membrane localization of the AP-4 complex. Traffic 12: 1604-1619, 2011.

25. Alvisi G, Paolini L, Contarini A, Zambarda C, Di Antonio V, Colosini A, Mercandelli N, Timmoneri M, Palù G, Caimi L, et al: Intersectin goes nuclear: Secret life of an endocytic protein. Biochem J 475: 1455-1472, 2018.

26. Jeppesen DK, Fenix AM, Franklin JL, Higginbotham JN, Zhang Q, Zimmerman LJ, Liebler DC, Ping J, Liu Q Evans R, et al: Reassessment of exosome composition. Cell 177: 428-445, 2019

27. Kowal J, Arras G, Colombo M, Jouve M, Morath JP, Primdal-Bengtson B, Dingli F, Loew D, Tkach M and Théry C: Proteomic comparison defines novel markers to characterize heterogeneous populations of extracellular vesicle subtypes. Proc Natl Acad Sci USA 113: E968-E977, 2016.

28. Radeghieri A, Savio G, Zendrini A, Di Noto G, Salvi A, Bergese P and Piovani G: Cultured human amniocytes express hTERT, which is distributed between nucleus and cytoplasm and is secreted in extracellular vesicles. Biochem Biophys Res Commun 483: 706-711, 2017

29. Berardocco M, Radeghieri A, Busatto S, Gallorini M, Raggi C, Gissi C, D'Agnano I, Bergese P, Felsani A and Berardi AC: RNA-Seq reveals distinctive RNA profiles of small extracellular vesicles from different human liver cancer cell lines. Oncotarget 8: 82920-82939, 2017.

30. Vescovi R, Monti M, Moratto D, Paolini L, Consoli F, Benerini L, Melocchi L, Calza S, Chiudinelli M, Rossi G, et al: Collapse of the plasmacytoid dendritic cell compartment in advanced cutaneous melanomas by components of the tumor cell secretome. Cancer Immunol Res 7: 12-28, 2019.

31. Horcas I, Fernández R, Gómez-Rodríguez JM, Colchero J, Gómez-Herrero $\mathbf{J}$ and Baro AM: WSXM: A software for scanning probe microscopy and a tool for nanotechnology. Rev Sci Instrum 78: 013705, 2007.

32. Maiolo D, Paolini L, Di Noto G, Zendrini A, Berti D, Bergese P and Ricotta D: Colorimetric nanoplasmonic assay to determine purity and titrate extracellular vesicles. Anal Chem 87 4168-4176, 2015

33. Zendrini A, Paolini L, Busatto S, Radeghieri A, Romano M, Wauben $\mathrm{MH}$, van Herwijnen MJ, Nejsum P, Borup A, Ridolfi A, et al: Augmented COlorimetric NANoplasmonic (CONAN) method for grading purity and determine concentration of EV microliter volume solutions. Front Bioeng Biotechnol 7: 452, 2019.

34. Salvi A, Vezzoli M, Busatto S, Paolini L, Faranda T, Abeni E, Caracausi M, Antonaros F, Piovesan A, Locatelli C, et al: Analysis of a nanoparticle-enriched fraction of plasma reveals miRNA candidates for down syndrome pathogenesis. Int J Mol Med 43: 2303-2318, 2019.

35. Sticht C, De La Torre C, Parveen A and Gretz N: Mirwalk: An online resource for prediction of microrna binding sites. PLoS One 18: e0206239, 2018

36. Dennis G, Sherman BT, Hosack DA, Yang J, Gao W, Lane HC and Lempicki RA: DAVID: Database for annotation, visualization, and integrated discovery. Genome Biol 4: P3, 2003.

37. Grossi I, Salvi A, Abeni E, Marchina E and De Petro G: Biological function of MicroRNA193a-3p in health and disease. Int J Genomics 2017: 5913195, 2017.

38. Faranda T, Grossi I, Manganelli M, Marchina E, Baiocchi G, Portolani N,Crosatti M, De Petro G and Salvi A: Differential expression profiling of long non-coding RNA GAS5 and miR-126-3p in human cancer cells in response to sorafenib. Sci Rep 9: 9118, 2019.

39. Grossi I, Arici B, Portolani N, De Petro G and Salvi A: Clinical and biological significance of miR-23b and miR-193a in human hepatocellular carcinoma. Oncotarget 8: 6955-6969, 2017

40. Théry C, Witwer KW, Aikawa E, Alcaraz MJ, Anderson JD, Andriantsitohaina R, Antoniou A, Arab T, Archer F, Atkin-Smith GK, et al: Minimal information for studies of extracellular vesicles 2018 (MISEV2018): A position statement of the international society for extracellular vesicles and update of the MISEV2014 guidelines. J Extracell Vesicles 7: 1535750, 2018.

41. Mollinari C, Racaniello M, Berry A, Pieri M, De Stefano MC, Cardinale A, Zona C, Cirulli F, Garaci E and Merlo D: MiR-34a regulates cell proliferation, morphology and function of newborn neurons resulting in improved behavioural outcomes. Cell Death Dis 6: e1622, 2015.
42. Agostini M, Tucci P, Steinert JR, Shalom-Feuerstein R, Rouleau M, Aberdam D, Forsythe ID, Young KW, Ventura A, Concepcion CP, et al: microRNA-34a regulates neurite outgrowth, spinal morphology, and function. Proc Natl Acad Sci USA 108: 21099-21104, 2011.

43. Morgado AL, Xavier JM, Dionísio PA, Ribeiro MF, Dias RB, Sebastião AM, Solá S and Rodrigues CM: MicroRNA-34a modulates neural stem cell differentiation by regulating expression of synaptic and autophagic proteins. Mol Neurobiol 51: 1168-11183, 2015.

44. Bavamian S, Mellios N, Lalonde J, Fass DM, Wang J, Sheridan SD, Madison JM, Zhou F, Rueckert EH, Barker D, et al: Dysregulation of miR-34a links neuronal development to genetic risk factors for bipolar disorder. Mol Psychiatry 20: 573-584, 2015.

45. Modi PK, Jaiswal S and Sharma P: Regulation of neuronal cell cycle and apoptosis by MicroRNA 34a. Mol Cell Biol 36: 84-94, 2016.

46. Wang X, Liu P, Zhu H, Xu Y, Ma C, Dai X, Huang L, Liu Y, Zhang L and Qin C: MiR-34a, a microRNA up-regulated in a double transgenic mouse model of alzheimer's disease, inhibits bcl2 translation. Brain Res Bull 28: 268-273, 2009.

47. Aranha MM, Santos DM, Solá S, Steer CJ and RodriguesMP: MiR-34a regulates mouse neural stem cell differentiation. PLoS One 6: e21396, 2011.

48. Dias BG, Goodman JV, Ahluwalia R, Easton AE, Andero R and Ressler KJ: Amygdala-Dependent Fear Memory Consolidation via miR-34a and Notch Signaling. Neuron 20: 906-918, 2014.

49. Liu N, Landreh M, Cao K, Abe M, Hendriks GJ, Kennerdell JR, Zhu Y, Wang LS and Bonini NM: The microRNA miR-34 modulates ageing and neurodegeneration in drosophila. Nature 15: 519-523, 2012.

50. Kennerdell JR, Liu N and Bonini NM: MiR-34 inhibits polycomb repressive complex 2 to modulate chaperone expression and promote healthy brain aging. Nat Commun 10: 4188, 2018.

51. Cheng L, Sharples RA, Scicluna BJ and Hill AF: Exosomes provide a protective and enriched source of miRNA for biomarker profiling compared to intracellular and cell-free blood. J Extracell Vesicles 3: 26, 2014

52. Leggio L, Vivarelli S, L'Episcopo F, Tirolo C, Caniglia S, Testa N, Marchetti B and Iraci N: MicroRNAs in parkinson's disease: From pathogenesis to novel diagnostic and therapeutic approaches. Int J Mol Sci 18: 2698, 2017.

53. Wang L and Zhang L: Circulating exosomal miRNA as diagnostic biomarkers of neurodegenerative diseases. Front Mol Neurosci 13: 53, 2020

54. Crescitelli R, Lässer C, Szabó TG, Kittel A, Eldh M, Dianzani I, Buzás EI and Lötvall J: Distinct RNA profiles in subpopulations of extracellular vesicles: Apoptotic bodies, microvesicles and exosomes. J Extracell vesicles 2: 12, 2013.

55. Lunavat TR, Cheng L, Kim DK, Bhadury J, Jang SC, Lässer C, Sharples RA, López MD, Nilsson J, Gho YS, et al: Small RNA deep sequencing discriminates subsets of extracellular vesicles released by melanoma cells-Evidence of unique microRNA cargos. RNA Biol 12: 810-823, 2015.

56. Enderle D, Spiel A, Coticchia CM, Berghoff E, Mueller R, Schlumpberger M, Sprenger-Haussels M, Shaffer JM, Lader E, Skog J and Noerholm M: Characterization of RNA from exosomes and other extracellular vesicles isolated by a novel spin column-based method. PLoS One 10: e0136133, 2015.

57. Ravanidis S, Bougea A, Papagiannakis N, Maniati M, Koros C, Simitsi A, Bozi M, Pachi I, Stamelou M, Paraskevas GP, et al: Circulating brain-enriched MicroRNAs for detection and discrimination of idiopathic and genetic parkinson's disease. Mov Disord 35: 457-467, 2020.

58. Bak M, Silahtaroglu A, Møller M, Christensen M, Rath MF, Skryabin B, Tommerup N and Kauppinen S: MicroRNA expression in the adult mouse central nervous system. RNA 14: 432-444, 2008.

59. Jauhari A, Singh T, Singh P, Parmar D and Yadav S: Regulation of miR-34 family in neuronal development. Mol Neurobiol 55: 936-945, 2018

60. Sarkar S, Jun S, Rellick S, Quintana DD, Cavendish JZ and Simpkins JW: Expression of microRNA-34a in alzheimer's disease brain targets genes linked to synaptic plasticity, energy metabolism, and resting state network activity. Brain Res 1646: 139-151, 2016.

61. Agostini M, Tucci P, Killick R, Candi E, Sayan BS, di Val Cervo PR, Nicoterad P, McKeon F, Knight RA, Mak TW and Melino G: Neuronal differentiation by TAp73 is mediated by microRNA-34a regulation of synaptic protein targets. Proc Natl Acad Sci USA 108: 21093-21098, 2011. 
62. Briggs CE, Wang Y, Kong B, Woo TU, Iyer LK and Sonntag KC: Midbrain dopamine neurons in parkinson's disease exhibit a dysregulated miRNA and target-gene network. Brain Res 1618: 111-121, 2015.

63. Delavar RM, Baghi M, Safaeinejad Z, Kiani-Esfahani A, Ghaedi K and Nasr-Esfahani MH: Differential expression of miR-34a, miR-141, and miR-9 in MPP ${ }^{+}$-treated differentiated PC12 cells as a model of parkinson's disease. Gene 662: 54-65, 2018.

64. Horst CH, Schlemmer F, de Aguiar Montenegro N, Domingues AC, Ferreira GG, da Silva Ribeiro CY, de Andrade RR, Del Bel Guimarães E, Titze-de-Almeida SS and Titze-de-Almeida R: Signature of aberrantly expressed microRNAs in the striatum of rotenone-induced parkinsonian rats. Neurochem Res 43: 2132-2140, 2018.

65. Ba Q, Cui C, Wen L, Feng S, Zhou J and Yang K: Schisandrin B shows neuroprotective effect in 6-OHDA-induced parkinson's disease via inhibiting the negative modulation of miR-34a on Nrf2 pathway. Biomed Pharmacother 75: 165-172, 2015.

66. Alural B, Ozerdem A, Allmer J, Genc K and Genc S: Lithium protects against paraquat neurotoxicity by NRF2 activation and miR-34a inhibition in SH-SY5Y cells. Front Cell Neurosci 9: 209, 2015.

67. Horst CH, Titze-De-Almeida R and Titze-De-Almeida SS The involvement of eag1 potassium channels and miR-34a in rotenone-induced death of dopaminergic SH-SY5Y cells. Mol Med Rep 15: 1479-1488, 2017.
68. Cosín-Tomás M, Antonell A, Lladó A, Alcolea D, Fortea J, Ezquerra M, Lleó A, Martí MJ, Pallàs M, Sanchez-Valle R, et al: Plasma miR-34a-5p and miR-545-3p as early biomarkers of alzheimer's disease: Potential and limitations. Mol Neurobiol 54: 5550-5562, 2017.

69. Mao S, Sun Q, Xiao H, Zhang C and Li L: Secreted miR-34a in astrocytic shedding vesicles enhanced the vulnerability of dopaminergic neurons to neurotoxins by targeting $\mathrm{Bcl}-2$. Protein Cell 6: 529-540, 2015.

70. Wan Y, Liu Y, Wang X, Wu J, Liu K, Zhou J, Liu L and Zhang C: Identification of differential microRNAs in cerebrospinal fluid and serum of patients with major depressive disorder. PLoS One 10: e0121975, 2015.

71. Ohmichi T, Mitsuhashi M, Tatebe H, Kasai T, El-Agnaf OA and Tokuda T: Quantification of brain-derived extracellular vesicles in plasma as a biomarker to diagnose parkinson's and related diseases. Park Relat Disord 61: 82-87, 2019.

This work is licensed under a Creative Commons Attribution-NonCommercial-NoDerivatives 4.0 International (CC BY-NC-ND 4.0) License. 